\title{
Author Correction: The experience of spasticity after spinal cord injury: perceived characteristics and impact on daily life
}

\author{
William Barry McKay ${ }^{1} \cdot$ William Mark Sweatman ${ }^{1,2} \cdot$ Edelle C. Field-Fote $^{1,3}$
}

Published online: 28 March 2018

(c) International Spinal Cord Society 2018

Correction to: Spinal Cord advance online publication 16 January 2018; https://doi.org/10.1038/s41393-017-0038-y.

Since the publication of this paper, the authors have become aware of important information which was omitted from the Methods section describing the reduction and analysis of data presented in Tables 2 and 3. The Methods section describes the subscales derived from experience of spasticity survey items; Table 1 shows the grouping of qualities of spasticity survey items that comprised each subscale. For each respondent, items in each subscale were summed to calculate individual subscale scores. Table 2 shows the qualities of spasticity subscale mean and SD values for "all," "tetraplegic" and "paraplegic" respondent groups. PRISM subscales were published by Cook et al (2007); Table 3 shows the PRISM subscale mean and SD values for the respondent groups. For both Tables 2 and 3, the possible range of scores for each subscale is given in parentheses.

The authors apologize for this error and any inconvenience caused.

The original article can be found online at https://doi.org/10.1038/ s41393-017-0038-y.

\footnotetext{
William Barry McKay

barry_mckay@shepherd.org

1 Shepherd Center, Crawford Research Institute, Atlanta, GA, USA

2 Georgia Gwinnett College, Lawrenceville, GA, USA

3 Division of Physical Therapy, Emory University School of Medicine, Atlanta, GA, USA
} 